\title{
QUANDO AS ESCOLAS PÚBLICAS SE PÕEM À PROVA DA INCLUSÃO ESCOLAR: SOBRE AS ARTES DE FAZER O COMUM - PLURAL - NAS ESCOLAS, EM BUSCA DO JUSTO
}

Flávia Schilling ${ }^{1}$; José Manuel Resende ${ }^{2}$

As políticas públicas no domínio da educação estão hoje munidas de ações públicas cheias de boas intenções. Entre muitas ações públicas destacamos dois princípios que desde a institucionalização da escola pública têm animado o debate político nacional e internacional. Um está ligado à igualdade de oportunidade escolar para todos; o segundo está associado à escolaridade obrigatória para todos os alunos em idade escolar. Contudo, a aplicação destes dois princípios ainda está aquém da sua concretização pública. As taxas de reprovação e do abandono ou da evasão escolares ainda são elevadas. É o que tem acontecido quer no Brasil, quer em Portugal. Neste sentido, a escola para todos é ainda uma miragem. Há uma percentagem de alunos que na idade escolar não completa a escolaridade obrigatória que tem estado a ser prolongada pelas políticas públicas.

Sendo atualmente de doze anos para os dois países, há coortes de alunos que não conseguem completar os diferentes ciclos de estudos que fazem parte da escolaridade obrigatória. Entre dificuldades de aprendizagem que muitos dos alunos dão mostra em cada ano letivo, e que se transformam em problemas públicos, categorizados como falta de eficiência na execução das ações públicas destinadas à diminuição do número de reprovações, paralelamente os Estados tendem a estabelecer medidas de permeação das escolas que conseguem melhores resultados nos exames finais de cada ciclo de ensino. 0 resultado destas medições é a construção de rankings escolares onde se hierarquizam as escolas de acordo com os resultados obtidos pelo conjunto de alunos matriculados em cada estabelecimento público e privado. Percebe-se, muito além das boas intenções, que muitas escolas reproduzem a violência e a discriminação, alijando os/as estudantes de seu direito a

\footnotetext{
${ }^{1}$ Socióloga, Professora Associada da Faculdade de Educação da USP, pesquisadora do CNPq, membro do Grupo de Pesquisas em Direitos Humanos, Memória, Política e Democracia do Instituto de Estudos Avançados da Universidade de São Paulo.

2 Sociólogo, Pesquisador integrado do CICS.NOVA, membro colaborador do PPGSP da Uenf, consultor externo do INCT-InEAC da UFF, membro colaborador do laboratório LeMetro da IFCS-UFRJ e membro colaborador do Observatório Permanente da Juventude do ICS da ULisboa.
}

(C) ETD-Educação Temática Digital Campinas, SP $\quad$ v.20 $\quad$ n.2 $\quad$ p. 301-304 abr./jun. 2018 
aprender. Aparecem como escolas injustas que reproduzem uma sociedade injusta. Porém, o que seria o justo? Quais seriam as artes possíveis para construir o comum nas escolas?

A par de todas estas questões cujos efeitos são notados nas sociabilidades escolares, existem outros problemas no interior das escolas que põem também à prova a convivência entre professores e alunos, entre os próprios alunos e também entre as suas famílias e as direções destas instituições.

Se, em Portugal, as nossas análises discutem as políticas de acolhimento organizadas por cada escola - da constituição das turmas ao diálogo com os pais sobre as regras que orientam a ordem da distribuição das grandezas escolares, associadas à disciplina e à aprendizagem - às políticas de habitabilidade dos espaços da escola, das acomodações necessárias para se estar em sala de aula para aprender, às medidas que permitam aos professores e alunos se sentirem confortáveis e em segurança nas suas escolas, sejam quais forem os seus territórios (biblioteca, cantina, laboratórios, etc.) - no Brasil há uma tendência à judicialização e medicalização das questões, tornando aquilo que é institucional e social em problemas individuais.

Nos dois países os problemas ainda são muitos e, por isso, a arquitetura dos espaços escolares é ainda pouco convidativa e estimulante quer para a aprendizagem adequada e ajustada às idades dos discentes, quer para a ação dos professores na instrução e na educação dos seus discípulos, quer ainda nas ações comuns e coordenadas entre todos para reduzir ou eliminar as ocorrências de indisciplina e de violência escolares, tanto no interior das escolas como fora dos seus muros.

Em muitos casos, os pais e encarregados de educação estão alheados dos problemas escolares dos seus filhos ou das crianças que estão sob sua tutela. Esse alheamento não é o produto de desinteresse ou de indiferença em relação àquilo que se passa na escola, mas é o fruto das dificuldades que estes sentem em entenderem as regras, quer ligadas aos processos de aprendizagem dos seus descendentes, quer ligadas aos processos de convivência escolar entre todos aqueles que povoam os estabelecimentos de ensino.

Todos estes fatos dão prova da incompletude da concretização das medidas políticas que visam construir uma escolarização pública para todos os alunos, independentemente da sua origem de classe, gênero, raça, etnia, residência geográfica ou confissão religiosa. Assim, é importante analisar com propriedade e com profundidade como é que se faz o comum nas escolas públicas. Só com análises profundas no âmbito das Ciências Sociais e das Ciências da Educação é que estamos em condições de compreender os problemas que se levantam hoje

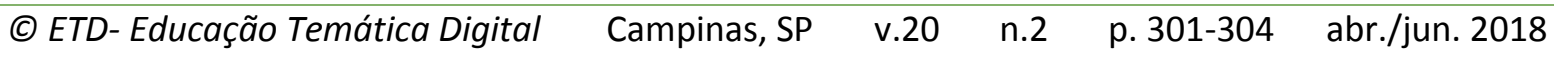


às políticas de inclusão escolar que são o espelho político das boas intenções acima mencionadas.

Face a estes desafios foi nosso propósito iniciar um diálogo entre pesquisadores brasileiros e portugueses sobre "as artes de fazer o comum nas escolas do ensino público" que se pretende profícuo e continuado no tempo. Na sequência desta vontade nasceu o desejo de se organizar um primeiro dossiê em que as diferentes autoras e os diferentes autores dos textos exploram questões diversas, mas ligadas a zonas problemáticas que estão conectadas com os formatos, modalidades e dispositivos de fazer o comum nas escolas públicas brasileiras e portuguesas.

No escopo de uma temática ainda pouco conhecida no domínio educativo lusobrasileiro, os artigos deste dossiê procuram dar conta a partir de análises distintas, mas complementares, de como as experiências escolares apreendidas por professores e alunos podem ser objeto de reflexões sobre as "artes de compor o comum no plural" nas instituições escolares e como a sua fabricação comporta debates quer sobre situações injustas, quer sobre os limites naquilo que é entendido como comum no âmbito das políticas de inclusão escolar.

Na verdade, a incompletude das políticas e ações públicas visando a construção de uma escola pública para todos, debate-se hoje com zonas problema ora ligadas a práticas de judicialização a partir de casos de indisciplina e de violência escolar, ora ligadas à tendência de medicalização que tem por objetivo reforçar a presença de dispositivos ligados à biomedicina e à psicologia comportamental. No quadro da entrada do judicial nos ambientes escolares as reflexões não deixam de trazer para o debate os efeitos da introdução de uma justiça restaurativa, trabalhada por mediadores, ou pelos conselhos tutelares, ou ainda pelo reforço de trabalho em torno dos argumentos em prol de justificações de práticas de justiça e não o seu contrário.

Outros olhares agora conectados com a vulnerabilidade experimentadas nas escolas, e com a problematização deste conceito, tornam possível trazer para a reflexão sociológica os processos de formação com vista a reavaliar práticas de ensino aprendizagem em contextos de elevada vulnerabilidade, e como as medidas de eficácia escolar, hoje insistentemente carreadas pelas políticas públicas, ora levantam desafios aos exercícios de legitimação da autoridade requerida pelos professores, ora tornam invisíveis situações e experiências rotineiras nas escolas que reforçam nos professores, alunos e pais sentimentos opressivos, e, por isso, inaceitáveis, ora ainda atentam contra as complexas fronteiras entre

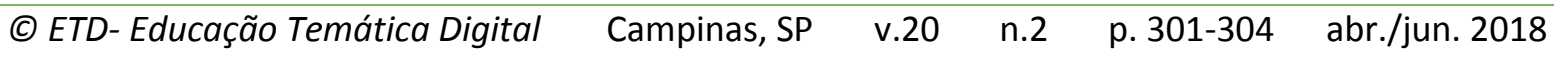


o íntimo e o público, quando estão em causa a implementação de ações públicas destinadas a educar a sexualidade.

Na mesma senda é analisada a aparente apatia e indiferença das questões políticas anunciadas por quem mede aquilo que habitualmente é qualificado como a "qualidade da democracia". Mais do que sinais incapacitantes dos alunos que se mostram alheados da intervenção pública em formatos tradicionais, os seus envolvimentos e ligações com a ambiência pública faz-se por outras experimentações baseadas em outros formatos criativos.

O pano de fundo de todas as incursões analíticas trazidas por este dossiê está ligado à extensa e complexa problemática das desigualdades escolares e das suas incidências nas vivências e experimentações resultantes das convivências monitorizadas nos espaços escolares A par das pesquisas organizadas para medir as desigualdades e os seus efeitos, quer na escola, quer nos seus entornos, o dossiê, não desconsiderando estas abordagens, trata-as indiretamente através das experiências apropriadas por docentes e discentes, quer a partir das sociabilidades dentro e fora das salas de aula, quer a partir de outras explorações ligadas à socialização política trabalhada na instituição, numa visão de educação para a cidadania mais ampla que a visão tradicional.

Ir mais a fundo na compreensão sobre as "artes de fazer o comum no plural" nas escolas públicas não pode nem descartar nem menorizar o que é que trazem para as arquiteturas escolares públicas de geometria variável, quer as políticas de acolhimento, quer as políticas de habitabilidade e de hospitalidade, quer ainda as políticas de decência e de justiça. Na persecução deste espírito o seu alcance para ser mais significativo requer o uso de outras metodologias associadas à aplicação de técnicas de observação de caráter mais presencial.

Dos mergulhos etnográficos às inquirições mediadas por casos dilemáticos que ocorram no seu interior ou na comunalidade política mais extensiva tornam possível analisar com maior finura as várias temperaturas que envolvem os processos escolares assentes em entendimentos plurais, quer sobre a figura do justo apropriada pelas experiências injustas e injustificadas, quer sobre o trabalho artesanal de confeccionar o comum nas escolas públicas. 